to APR30 or APR20 at Week 16 (early escape) or Week 24. Double-blind APR treatment continued to Week 52; patients could continue APR during an open-label, long-term treatment phase for up to 5 years treatment. Visits in years 2,3 , and 4 were scheduled at 13 -week intervals. Safety was assessed at each visit throughout the study, and results are summarized here by exposure.

Results: A total of 1493 patients were randomized and received $\geq 1$ dose of study medication (PBO: $n=495 ;$ APR30: $n=497$; APR20: $n=501$ ). At the 4-year data cut, the numbers of patients receiving APR30 and APR20 in each exposure period were 1441 in Weeks 0 to $\leq 52,1028$ in Weeks $>52$ to $\leq 104,865$ in Weeks $>104$ to $\leq 156$, and 767 in Weeks $>156$ to $\leq 208$. During the 0 - to $\leq 52$-week APR-exposure period, adverse events (AEs) occurring in $\geq 5 \%$ of APR30-exposed patients were diarrhea, nausea, headache, upper respiratory tract infection, and nasopharyngitis (Table). Most diarrhea and nausea AEs were reported within the first 2 weeks of treatment and usually resolved within 4 weeks; the frequency of gastrointestinal AEs decreased with longer APR30 exposure, and the frequency of other common AEs either decreased or remained stable with prolonged exposure (Table). Most AEs were mild/moderate in severity. During Weeks $>156$ to $\leq 208$ of APR exposure, the discontinuation rate due to AEs was $1.7 \%$ with APR30, and the rate of serious AEs (SAEs) was $7.0 \%$, consistent with earlier periods; most SAEs occurred in 1 patient each. Rates were very low for major cardiac events, malignant neoplasms, and serious opportunistic infections, comparable to the first year of treatment. Rates of depression remained very low in Weeks $>156$ to $\leq 208$. Marked laboratory abnormalities were infrequent, and most returned to baseline with continued treatment.

Conclusions: APR30 demonstrated a favorable safety profile and was well tolerated for up to 208 weeks, marked by the lack of accumulation of immunosuppression or need for specific laboratory monitoring. The incidence of AEs remained stable or decreased with long-term exposure to APR30.

Disclosure of Interest: P. Mease Grant/research support from: Abbott, Amgen, Biogen Idec, BMS, Celgene Corporation, Genentech, Janssen, Eli Lilly, Novartis, Pfizer, Roche, UCB, Consultant for: Abbott, Amgen, Biogen Idec, BMS, Celgene Corporation, Genentech, Janssen, Eli Lilly, Novartis, Pfizer, Roche, UCB, Speakers bureau: Abbott, Amgen, Biogen Idec, BMS, Genentech, Janssen, Eli Lilly, Pfizer, UCB, D. Gladman Grant/research support from: AbbVie, Amgen, BMS, Celgene Corporation, Janssen, Novartis, Pfizer, UCB, Consultant for: AbbVie, Amgen, BMS, Celgene Corporation, Janssen, Novartis, Pfizer, UCB, J. Gomez-Reino Grant/research support from: Roche and Schering-Plough, Consultant for: BMS, Pfizer, Roche, Schering-Plough, UCB, S. Hall Consultant for: Boehringer Ingelheim, MSD, Roche, Schering-Plough, Servier, Wyeth, Paid instructor for: Amgen, AstraZeneca, Boehringer Ingelheim, Centocor, GSK, MSD, Pfizer, Sanofi Aventis, Sanofi Pasteur, Schering-Plough, Serono, Wyeth, Speakers bureau: Boehringer Ingelheim, GSK, MSD, Pfizer, Roche, Sanofi Aventis, ScheringPlough, Wyeth, A. Kavanaugh Grant/research support from: Abbott, Amgen, AstraZeneca, BMS, Celgene Corporation, Centocor-Janssen, Pfizer, Roche, UCB, E. Lespessailles Grant/research support from: Amgen, Eli Lilly, Novartis, Servier, Speakers bureau: Amgen, Eli Lilly, Novartis, Servier, G. Schett Grant/research support from: Abbott, Celgene Corporation, Roche, UCB, Consultant for: Abbott, Celgene Corporation, Roche, UCB, M. Paris Employee of: Celgene Corporation, L. Teng Employee of: Celgene Corporation, J. Wollenhaupt Grant/research support from: Abbott, BMS, MSD, Pfizer, UCB, Consultant for: Abbott, BMS, MSD, Pfizer, UCB

DOI: 10.1136/annrheumdis-2017-eular.3840

\section{AB0786 SYSTEMATIC REVIEW OF MEASUREMENT PROPERTIES OF PATIENT REPORTED OUTCOME MEASURES IN PSORIATIC ARTHRITIS: A GRAPPA-OMERACT INITIATIVE}

P. Højgaard ${ }^{1,2}$, L. Klokker ${ }^{1}$, A.-M. Orbai ${ }^{2}$, K. Holmsted ${ }^{1}$, E.M. Bartels ${ }^{1}$, Y.Y. Leung ${ }^{2}$, N. Goel ${ }^{2}$, M. de Wit ${ }^{2}$, D. Gladman ${ }^{2}$, P. Mease ${ }^{2}$, L. Dreyer ${ }^{1}$, L.E. Kristensen ${ }^{1}$, O. FitzGerald ${ }^{2}$, W. Tillett ${ }^{2}$, L. Gossec ${ }^{2}$, P. Helliwell ${ }^{2}$, V. Strand ${ }^{2}$, A. Ogdie ${ }^{2}$, C. Terwee ${ }^{2}$, R. Christensen ${ }^{1,2}$ on behalf of GRAPPA-OMERACT PsA Core Set Working Group. ${ }^{1}$ The Parker Institute, Frederiksberg and Bisbebjerg Hospital, Copenhagen, Denmark, Frederiksberg, Denmark; ${ }^{2}$ GRAPPA-OMERACT PSA Core Set Working Group, International organisation,

Background: An updated psoriatic arthritis (PsA) core domain set (COS) for randomized controlled trials (RCTs) was endorsed at the Outcome Measures in Rheumatology (OMERACT) meeting in 2016 and reflects the patient and physician perspectives.[1]

Objectives: To synthesise the evidence on measurement properties of Patient Reported Outcome Measures (PROMs) in PsA in order to contribute to the development of a PsA core outcome measurement set (COMS) for RCTs adhering to the OMERACT filter 2.0 Framework.[2]

Methods: A systematic literature search was performed in EMBASE, MEDLINE and PsycINFO to identify studies published in English on PROM measurement properties in PsA. Two independent reviewers rated the quality of studies according to COnsensus-based Standards for the selection of health Measurement INstruments (COSMIN) guidelines,[3] extracted data on measurement properties and performed a qualitative evidence synthesis.

Results: Of 4703 identified references, 162 were read in full-text and 44 included in the systematic review (SR). Thirty-nine instruments, consisting of one or more scales, were analysed. PROMs measuring core set domains with at least fair quality evidence for good validity and reliability (and without evidence for inadequate measurement properties) were: Stockerau Activity Score for PsA (German) for the Musculoskeletal Disease Activity domain; the Psoriatic Symptom Inventory for Skin Disease Activity; the 36-Item Short Form Health Survey Physical Function scale and to a lesser extent the Health Assessment Questionnaire Disability Index and Bath Ankylosing Spondylitis Functional Index for Physical Function; the Psoriatic Arthritis Quality of Life Questionnaire, the Psoriatic Arthritis Impact of Disease questionnaire and VITACORA-19 (Spanish) for Health related Quality of Life/Life Impact; the Functional Assessment of Chronic Illness Therapy-Fatigue Scale for Fatigue, and the Social Role Participation Questionnaire for Participation. Evidence for content validity was lacking for most of these PROMs.

Conclusions: At least one PROM with some evidence for good validity and reliability was available for five out of eight inner circle domains of the PsA COS. Lack of content validity evidence constitutes a critical barrier for application to the PsA COS per the OMERACT Filter 2.0 Instrument Selection Algorithm [2]. This SR serves as a guide for additional research to increase knowledge of PROM measurement properties in PsA followed by stakeholder consensus for developing a PsA COMS.

PROSPERO:CRD42016032546

\section{References:}

[1] Orbai AM, de WM, Mease $P$ et al. International patient and physician consensus on a psoriatic arthritis core outcome set for clinical trials. Ann Rheum Dis 2016. doi: 10.1136.

[2] Martin Boers, John Richard Kirwan, Peter Tugwell et al. The OMERACT handbook. Updated May 2016, http://www.omeract.org

[3] Terwee CB, Mokkink LB, Knol DL et al. Rating the methodological quality in systematic reviews of studies on measurement properties: a scoring system for the COSMIN checklist. Qual Life Res 2012;21:651-7.

Disclosure of Interest: P. Højgaard Speakers bureau: Received speaking fees once from Celgene and UCB not related to the current work, L. Klokker: None declared, A.-M. Orbai: None declared, K. Holmsted: None declared, E. Bartels: None declared, Y. Y. Leung: None declared, N. Goel Employee of: QuintilesIMS, M. de Wit: None declared, D. Gladman: None declared, P. Mease: None declared, L. Dreyer: None declared, L. Kristensen: None declared, O. FitzGerald: None declared, W. Tillett: None declared, L. Gossec: None declared, P. Helliwell: None declared, V. Strand: None declared, A. Ogdie: None declared, C. Terwee: None declared, R. Christensen: None declared

DOI: 10.1136/annrheumdis-2017-eular.4631

\section{AB0787 STUDY OF SERUM SCLEROSTIN LEVELS IN ASSOCIATION TO ENTHESIAL ULTRASONOGRAPHY IN EGYPTIAN PSORIATIC ARTHRITIS PATIENTS}

R. Elmallah ${ }^{1}$, E. EL Attar ${ }^{1}$, D. Farrag ${ }^{1}$, D. Samaha ${ }^{2}$ on behalf of responsible for part of clinical measuring of sclerostin level. ${ }^{1}$ Rheumatology \& Rehabilitation; ${ }^{2}$ Clinical \& Chemical Pathology, Faculty of Medicine Ainshams University, Cairo, Egypt

Background: Psoriatic arthritis (PsA) is characterized by focal bone erosions and new bone formation, suggesting an uncoupling of osteoblast-osteoclast homeostasis [1]. Serum sclerostin is a protein inhibitor of wnt signaling pathway of bone formation implicated in the suppression of bone repair in inflammatory arthritis. The role of sclerostin in osteoimmunology and inflammatory arthritides is still controversial [2].

Objectives: This study aimed at measuring serum sclerostin in psoriatic arthritis men and to correlate its levels with disease activity scores, ultrasonographic findings and bone mineral density in those patients

Methods: This study included 30 male patients diagnosed with Psoriatic arthritis (PsA), 15 healthy age and sex matched volunteers as control group. Patients disease activity index measured. Clinical assessment by Leed's enthesitis Index (LEI) [3], Spinal manifestations scored according to Bath Ankylosing Spondylitis Activity Index [4], Serum sclerostin measured using enzyme linked immunosorbent assay. Ultrasonography of enthesis at Leeds enthesitis sites [5] and dual energy $x$-ray absorbiometry (DEXA) at the lumbar spine.

Results: The study included 30 PsA male patients with a mean age of $43.33 \pm 8.33$ mean, body mass index (BMI) of $26.87 \pm 2.63$ and 15 healthy age and sex matched

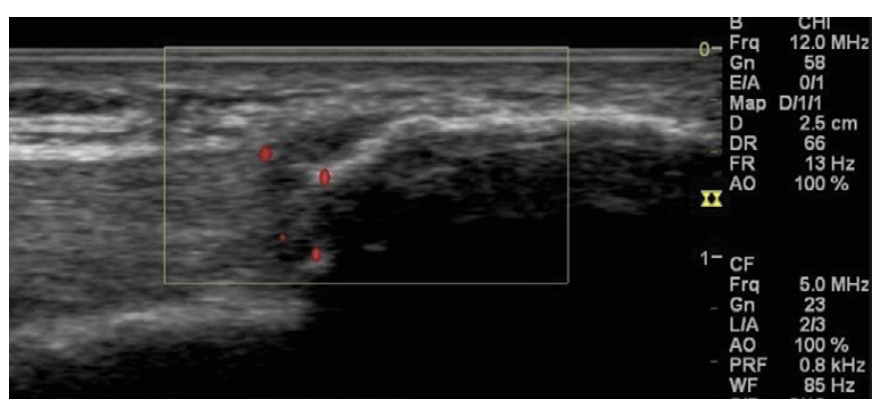

Figure 1. Ultrasonographic longitudinal scan of the tendoachillis showing hypoechoic area of edema \& power Doppler signal at insertion. 
controls with a mean age of $42.12 \pm 7.22$ mean BMl of $25.87 \pm 3.51$ with an unsignificant difference between two groups.

Serum sclerostin level significantly higher in PsA patients compared to controls with a mean of $(0.64$ and $0.37 \mathrm{ng} / \mathrm{ml})$ respectively, positive significant correlation with patients' age, disease activity scores, ultrasonographic findings of inflammation and damage at the enthesis as well as negative correlation with DEXA at lumbar spine. A positive though non-significant correlation detected between serum sclerostin and Leeds clinical enthesitis index (LEI) and CRP.

Conclusions: sclerostin plays important role in pathogenesis of psoriatic arthritis and associated with bone damage either systemic or localized. Further studies for the effect of treatment on serum sclerostin, ultrasonographic and bone mineral density findings is recommended

References:

[1] Homaira Rahimi \& Christopher T. Ritchlin. Altered Bone Biology in Psoriatic Arthritis. Curr Rheumatol Rep (2012) 14:349-357.

[2] Matzelle MM, Gallant M, Condon KW, et al. Resolution of inflammation induces osteoblast function and regulates the Wnt signaling pathway. Arthritis Rheum 2012; 64:1540-1550.

[3] Healy PJ and Helliwell PS: "Measuring clinical enthesitis in psoriatic arthritis: assessment of existing measures anddevelopment of an instrument specific to psoriatic arthritis." Arthritis Care and Research 2008; 59(5):686-691.

[4] Garrett S, Jenkinson T, Kennedy LG et al. A new approach to defining disease status in ankylosing spondylitis: the Bath ankylosing spondylitis disease activity index. J Rheumatol (1994); 21 (12): 2286-2291.

[5] Ibrahim G, Groves C, Chandramohan M, Beltran A, Valle R, Reyes B, Healy $P$, Harrison A and Helliwell P S. Clinical and Ultrasound Examination of the Leeds Enthesitis Index in Psoriatic Arthritis and Rheumatoid Arthritis. ISRN Rheumatology Volume 2011(2011), Article ID 731917, http://dx.doi.org/10.5402/2011/731917.

Disclosure of Interest: None declared

DOI: 10.1136/annrheumdis-2017-eular.1317

\section{AB0788 DIFFERENCES IN THE PHENOTYPIC EXPRESSION OF RECENT ONSET PSORIATIC ARTHRITIS AMONG MEN AND WOMEN BASELINE DATA FROM THE REAPSER STUDY}

R. Queiro, A. Laiz Alonso, H.S. Park, C. Montilla Morales, E. Galíndez Agirregoikoa, J.J. Bethencourt Baute, S. Bustabad Reyes, P. Tejón Menéndez, M.Á. Belmonte, J.A. Pinto Tasende, E. Alonso Blanco Morales, J. Ramír. Rheumatology, Hospital Universitario Central de Asturias (Coordinating Center), Oviedo, Spain

Background: The natural history of psoriatic arthritis (PSA) according to gender of patients is an aspect of the disease only partially studied. In prospective PsA cohorts such information is barely known.

Objectives: To analyze baseline gender differences in the REAPSER cohort (Psoriatic Arthritis Registry of the Spanish Society of Rheumatology).

Methods: Observational, multicenter study (34 centers), with consecutive inclusion. We included adults of both sexes 18 years of age or older with PsA that met CASPAR criteria, and duration of less than two years since the appearance of symptoms attributed to PsA. Annual follow-up visits will be carried out for 5 years. Measurements: socio-demographic data; employment status and impact of the disease; family history of PsA and other inflammatory diseases; comorbidities and treatment; lifestyle; use of health services; clinical status at the time of diagnosis of PsA; anthropometric data; clinical evaluation of PsA manifestations; radiographic

\begin{tabular}{lccc}
\hline Parameter & Men $(\mathrm{N}=142)$ & Women $(\mathrm{N}=68)$ & P values \\
\hline Age (years) & $50.2(13.8)$ & $49.6(14.1)$ & $\mathrm{NS}$ \\
University studies & $18.3 \%$ & $16.2 \%$ & $\mathrm{NS}$ \\
Active worker & $65 \%$ & $49.3 \%$ & $<0.001$ \\
BMI & $27.3(4.8)$ & $28.5(6)$ & $\mathrm{NS}$ \\
Waist-hip index & $0.94(0.1)$ & $0.87(0.1)$ & $<0.001$ \\
Smoker & $29.6 \%$ & $32.4 \%$ & $\mathrm{NS}$ \\
Alcohol consumption & $45.1 \%$ & $16.2 \%$ & $<0.001$ \\
Psoriasis family history & $40.1 \%$ & $45.6 \%$ & $\mathrm{NS}$ \\
PsA family history & $8.5 \%$ & $10.3 \%$ & $\mathrm{NS}$ \\
Charlson's Cl (>3) & $18.3 \%$ & $17.6 \%$ & $\mathrm{NS}$ \\
Depression & $7.7 \%$ & $19.4 \%$ & 0.014 \\
Common Psoriasis & $81 \%$ & $61.8 \%$ & 0.003 \\
Pustular Psoriasis & $2.1 \%$ & $11.8 \%$ & 0.006 \\
Onicopathy & $59 \%$ & $49 \%$ & $\mathrm{NS}$ \\
PASI & $1.5(0.6-4.4)$ & $1.2(0.6-3)$ & $\mathrm{NS}$ \\
Peripheral pattern & $80.3 \%$ & $83.8 \%$ & $\mathrm{NS}$ \\
Axial pattern & $7 \%$ & $1.5 \%$ & $\mathrm{NS}$ \\
Mixed Pattern & $12.7 \%$ & $14.7 \%$ & $\mathrm{NS}$ \\
BASDAI (0-10) & $4.1(2.2-6)$ & $4.8(2.4-7.3)$ & 0.008 \\
BASFI (0-10) & $1.8(0.4-4.5)$ & $2.9(1.4-4.7)$ & 0.065 \\
Dactylitis & $31.4 \%$ & $47.1 \%$ & 0.028 \\
Pain (0-10) & $4.5(2-7)$ & $6(4-7.5)$ & 0.021 \\
PGA (0-10) & $5(3-7)$ & $6(3.5-8)$ & 0.042 \\
ESR (mm/h) & $12(5-20)$ & $21(10-29.5)$ & 0.001 \\
\hline CI: comorbidity & & & \\
\hline
\end{tabular}

Cl: comorbidity index. PASI: Psoriasis Area and Severity Index. PGA: Patient's Global Assessment. Data are expressed in percentages, means with SD (Standard Deviation), medians and IQR (Interquartile Range). There were no significant differences in SJC, TJC or PsAID (Psoriatic Arthritis Impact of Disease) evaluation; analytical determinations; treatment of PsA. The study has been approved by the Ethical committees of the participating centers. Comparative statistical analysis: for qualitative variables, the $\chi$-square or the Fisher exact statistic were used. For non-normal quantitative variables, non-parametric tests were used and for normal quantitative variables, Student's t-test was used.

Results: The results are expressed in the table.

Conclusions: The baseline data from this prospective cohort point to significant differences in the phenotypic expression of PsA between men and women. Thus, in women, the prevalence of dactylitis and pustular psoriasis was higher, there were higher rates of depression and a perception of higher disease activity. Women scored higher on the pain linked to their arthritis and the activity of axial disease. They also had biological activity parameters (ESR) higher than that of men. It is necessary to determine if these differences are maintained or change over time. Disclosure of Interest: None declared

DOI: 10.1136/annrheumdis-2017-eular.5039

\section{AB0789 THE PSORIATIC ARTHRITIS PATIENT'S JOURNEY: SPECIAL EMPHASIS ON DIAGNOSIS AND TREATMENT DELAYS}

S. Moyano, M. Brom, F.B. Mollerach, L.E. Pompermayer, M.L. Acosta Felquer, M. Scolnik, J. Marin, L.G. Ferreyra Garrott, L.J. Catoggio, J.E. Rosa,

E.R. Soriano. Rheumatology, Hospital Italiano de Buenos Aires, Buenos Aires, Argentina

Background: A delay in diagnosis and treatment of Psoriatic Arthritis (PsA) is associated with increased disability and damage in the long term. There is currently scarce data available about diagnosis delay, referrals delays, and time to first treatment in patients with PSA in developing countries.

Objectives: To describe the journey of patients with psoriatic arthritis, with special emphasis on diagnosis and treatment delays.

Methods: All patients with PsA registered in the Rheumatology Unit data base (between 2000-2016), with complete data, were included. Electronic medical records were manually revised, and the following data were obtained: date of first visit to a Dermatologists due to Psoriasis ( $\mathrm{PsO}$ ) symptoms, date of $\mathrm{PsO}$ diagnosis, date and type of first musculoskeletal symptom, specialty of physician seen at first visit for musculoskeletal symptoms, date of PsA diagnosis, date and reason for prescription of first Disease Modifying anti-Rheumatic Drug (DMARD) Primary outcome variable was mean lag time between first musculoskeletal symptom and diagnosis of PsA. Other variables calculated were: mean lag time between first musculoskeletal symptom and first physician encounter because of those symptoms, mean lag time to first DMARD and mean lag time between $\mathrm{PsO}$ diagnosis and PsA diagnosis. Variables associated with a delay in PsA diagnosis (more than one year delay) were analyzed in multivariable analysis (logistic regression).

Results: 93 patients were included, mean age 60.8 years (SD: 15.3 ), 61\% males. Mean age at time of PsA diagnosis was 52 years (SD: 14.8). The most common musculoskeletal symptom was arthralgia (46\%), followed by arthritis $(37 \%)$, enthesitis $(6 \%)$, low back pain $(6 \%)$, and dactylitis $(4 \%)$. Mean lag time between first musculoskeletal symptoms and visit to a physician because of those symptoms was 16,8 months (SD: 44,4) (median: 1,92 (IQR: 0,35-11,6). In Only $33 \%$ of the cases the first specialist seen was a Rheumatologist. Mean lag time between first musculoskeletal symptom and diagnosis of PsA was 19,2 (SD: 28,8) months (Median: 7,2 (IQR: 2,4-21,6 months). In 90 patients (97\%), the diagnosis of $\mathrm{PsO}$ preceded the diagnosis of PsA, a mean time of 15.1 years (SD: 14.4). 83 patients (89\%) received traditional DMARDs, $82 \%$ because of the musculoskeletal symptoms, with a mean lag time between PsA diagnosis and initiation of DMARDs of 11,4 months (SD: 31,2$)$ (Median: 0,48 (IQR: 0-4,3) months). Forty-three patients (46.2\%) had a delay on PsA diagnosis equal or greater than 1 year. In logistic regression analysis, including age, sex, first specialist seen and type of musculoskeletal symptom, none was independently associated with a delay equal or greater than 1 year in PsA diagnosis.

Conclusions: Mean time between symptoms' onset and PsA diagnosis was relatively short. However, a delay greater that one year was observed in almost half of patients. As none of the variables studied was associated with a delay in diagnosis, more studies are needed to identify potential actions that would help reducing this delay.

References:

[1] Kane D, et al. Rheumatology 2003;42:1469-1476.

[2] Haroon M, et al. Ann Rheum Dis 2014:0:1-6.

[3] Gladman DD, et al. Arthritis Rheum 1998;41:1103-1110.

Disclosure of Interest: None declared

DOI: 10.1136/annrheumdis-2017-eular.2231

\section{AB0790 HYPERURICEMIA IN PSORIATIC ARTHRITIS: PREVALENCE AND ASSOCIATED FACTORS}

T. Gudu, A. Peltea, A. Balanescu, V. Bojinca, D. Opris, D. Predeteanu, R. Ionescu. Rheumatology, Sf Maria Hospital, UMF Carol Davila, Bucharest, Bucharest, Romania

Background: Hyperuricemia is frequent in psoriatic arthritis (PsA) and it seems to be related to metabolic syndrome rather than to extensive psoriatic skin disease [1]. 